\title{
Being a Next of Kin-Experiences of Burden and Quality of Life
}

\author{
Elisabeth Liedström ${ }^{\text {1 }}$, Annica Kihlgren1, Kirsti Skovdahl1,2, Jenny Windahl1 \\ ${ }^{1}$ School of Health and Medical Sciences, University of Örebro, Örebro, Sweden \\ ${ }^{2}$ Faculty of Health Sciences, Buskerud University College, Buskerud, Norway \\ Email: elisabeth.liedstrom@spray.se, annica.kihlgren@oru.se, kirsti.skovdahl@hibu.no, jenny.windahl@oru.se
}

Received 2 February 2014; revised 31 March 2014; accepted 4 April 2014

Copyright (C) 2014 by authors and Scientific Research Publishing Inc.

This work is licensed under the Creative Commons Attribution International License (CC BY). http://creativecommons.org/licenses/by/4.0/

(c) (i) Open Access

\begin{abstract}
Aim and Objectives: To increase the understanding of next of kin's life situation in the context of supporting persons who are long term ill, disabled and/or older by describing their experienced burden and quality of life and also the relationship between QoL, burden and socioeconomic variables. Methods: Cross-sectional, descriptive and correlative design. Eighty-four next of kin answered two questionnaires: the Caregiver Burden Scale and the Subjective Quality of Life. Results: Next of kin experienced a high burden in their life situation although they, at the same time, experienced a good quality of life. In the results gender differences were found. Females next of kin to a higher extent were disappointed, more emotionally involved, and they also estimated their economic situation as more unsatisfactory than the males next of kin. Conclusion: Healthcare personnel meet next of kin, persons in need of care, within all healthcare and social care in society. Therefore it is important to have a general knowledge and ability to understand the next of kin's life situation, thus making it possible to focus the nursing interventions on individual support regardless of the care receiver's diagnosis.
\end{abstract}

\section{Keywords}

Next of Kin; Informal Caregiver; Quality of Life; Burden; Life Situation

\section{Introduction}

Over the next fifty years the care needs will increase in most parts of the world due to changes in fertility and life expectancy, combined with changes in the number of persons with severe chronic illnesses, disabilities and/or older age. At the same time, the number of adults who are economically active or available to fulfil care-

*Corresponding author. 
giving roles will change, and in some countries it will decrease. Though families will continue to play a central role, countries must ensure that resources are available to address the growing needs [1].

In the United States, $29 \%$ of the population provide care to someone who is ill, disabled or older [2]; in England $12 \%$ of people aged 16 or over are giving care to an ill, disabled or older person [3]. Sweden has a population of nine million people of which $18 \%$ aged 18 and over give care to a person with long term illness, disabilities and/or are older. At least 900,000 of these are of working age [4]. In the present study, next of kin refers to the person that is giving informal care to the care receiver, and they do not need to be blood relatives.

\section{Background}

A long-term illness or disability affects not only the person in need of care, but also his/her next of kin. The ill, disabled and/or older persons are increasingly living in their homes today and next of kin's commitment is also increasing [5]. Being a next of kin can be experienced as both positive and negative. The next of kin may experience burden and lack of freedom but simultaneously feel satisfaction and joy. The negative and positive experiences are not mutually exclusive [6]. To most people, giving care to another person is self-evident. It may be seen as a valuable part of being human [7].

The next of kin do not belong to the formal healthcare organization, and does not possess any education or, in general, no economical compensation for the care [8]. The next of kin's own support from the healthcare system, to make them cope in their informal caring role, may be invisible or visible. The invisible caregiving means the qualitative dimensions and relationships between the parts as, for example, the next of kin feels secure that the care receiver gets a good treatment from the personnel in the healthcare or that the next of kin feels confirmed in the meeting with the personnel. Visible support refers to the support that facilitates for the next of kin; for example, economical support or day-care for the care receiver [9].

A distinction can be made between two types of next of kin: those who perceive the care as a voluntary act of compassion and those who find the care generally considered as an unavoidable obligation. Whether the next of kin feel they have a choice to be caregivers or not, it is relevant if they perceive a burden in providing care or not [10].

During the last few years, several studies have been published regarding next of kin's strain, due to giving care to a care receiver. The studies mostly focused on giving care to persons with a specific diagnosis [11]-[16], and examples of this are given below. For instance, giving care to adult children with acquired brain injury could be experienced as extremely stressful. When the child is diagnosed, feelings of stress about the cause of the acquired brain injury may arise, and the planning for long-term accommodation for their child can be experienced as stressful [11]. Another example is that spouses, parents or siblings who were caregivers to persons with traumatic brain injury perceived less burden and depression when they had a strong social and family life [12]. All next of kin of persons with Huntington's disease reported multiple aspects of emotional distress. Being a next of kin was described as experiencing disintegration of one's life. Spouses were distressed by the loss of the relationship with their spouse as an intimate partner [13]. Next of kin to young adults with multiple sclerosis experienced caregiver burden, i.e., physical, psychological, emotional, social, and economic stressors. Next of kin who experience burden are at higher risk of depression and lower quality of life [14]. Next of kin to older persons with stroke have a complex life situation with negative effects on their perceived quality of life and psychosocial well-being [15]. Another study focused on next of kin's care of older persons with cognitive disabilities such as dementia; all next of kin felt a heavy burden, and they expressed anger, worry, weariness, guilt, distress and isolation. The quality of the relationship preceding the onset of dementia had a bearing on the next of kin's situation [16].

\subsection{Burden as a Concept}

Burden, as a research construct, was developed by Zarit et al. [17] for next of kin of persons with dementia. Next of kin's burden is defined as the extent to which next of kin perceived their emotional or physical health, social life and economic status to be negatively affected as a result of caring for the care receiver. Next of kin who experienced burden expressed feelings of being isolated, angry, and anxious, and they were more likely to have a risk of depression and a lower quality of life [17]. There is a distinction between objective and subjective burden. Objective burden, physical work of caregiving, is defined as the extent of interferences or changes in different aspects of the next of kin's life and household. Subjective burden is defined as the next of kin's atti- 
tudes for or against emotional reactions to the caregiving experience, as worries, anxiety and frustration [18] [19].

\subsection{Quality of Life as a Concept}

The concept of QoL is well established, both in health sciences and social sciences, but there is no consensus about what the nature of the concept of QoL means [20]. The meaning of QoL depends on the context in which it is used; the theoretical perspective means different things to different people [21]. A distinction is made between QoL and a health-related quality of life (HRQoL), where the latter is a concept that includes aspects which are influenced by disease [20]. The QoL elucidates this as an equivalent to "well-being”, a psychological and emotional term, and associated with the experiences of individuals. A person experiences a high QoL when the person is active, has good interpersonal relations, and has self-esteem and a basic mood of happiness [22].

\subsection{Rationale for This Study}

As the next of kin appear to be a heterogeneous group, with different needs and experiences of being a next of kin, it is of importance for healthcare personnel to have a general knowledge and ability to understand the next of kin's life situation, regardless of the care receiver's diagnosis, as they meet next of kin to persons in need of care within all healthcare and social care in society. Earlier research has mostly focused on caregiving of next of kin to persons with specific diagnoses. Therefore there is a need to increase the understanding of next of kin's life situation and burden, without the next of kin's experiences being related to the care receiver's specific diagnosis. The aim of the present study was to describe next of kin's experienced burden and QoL, and the relationship between QoL, burden and socioeconomic variables.

\section{Method}

\subsection{Design}

The study had a quantitative approach, with a descriptive and correlative design, which was part of a cross-sectional research project, consisting of four questionnaires. In the present study, two of the four questionnaires were included. The two questionnaires, not included in this study were a questionnaire on Chronic Sorrow and a questionnaire regarding satisfaction in the informal caregiving, working methods and attitudes.

The research project was approved by the regional Ethical Review Board in Sweden (dnr 2011/009).

\subsection{Participants}

A pilot study, including two next of kin, was made to test the time required and if there was any difficulty to complete the questionnaires. The next of kin had no difficulties to fill in the questionnaires; it took them about 30 - 40 minutes to complete.

There was a broad nationwide recruitment of next of kin to the present study. Nationwide in Sweden, three general associations for next of kin and 29 associations directed to a specific diagnosis were contacted by mail or telephone, inquiring if they were willing to give brief information to their members about the present study to help with the recruitment of respondents. Nineteen associations were willing to publish study information on their websites, in monthly journals, newsletters, Blogs or Facebook pages, and gave information in person at their meetings. The superscription of the published study information was; "To next of kin to a person in need of care”. The information also described that the aim of the study was to increase understanding of the next of kin's life situation in the context of giving support to a person who is long term ill, disabled and/or older. The inclusion criterion was to be a self-identified next of kin to a long term ill, disabled and/or older person in need of care. There were no restrictions about who could or could not be the next of kin; it did not have to be a blood relative. There were no restrictions about the care receiver's age, gender or diagnosis, nor the intensity and duration of the next of kin's caregiving. The next of kin who responded $(n=111)$ and were interested to participate in the study had care receivers with somatic and/or mental illnesses. There was no possibility to identify from which association each respondent had received information regarding the study. These respondents received more detailed written information about the study, an informed consent form, the four questionnaires and a prepaid envelope for their return, sent by post. Eighty-four next of kin completed the questionnaires and returned them together with the signed informed consent to the first author, giving a response rate of $76 \%$. Of these 84 , 
eight next of kin answered after one reminder, and six next of kin answered after two reminders, sent out with approximately two weeks in between. Data collection took place from June 2012 to December 2012.

\subsection{Data Collection}

Demographic data was collected about the next of kin's age, gender, civil status, what kind of relationship the next of kin had to the care receiver, and if they were living together. Additional questions regarded what kind of employment the next of kin had, for how long time the care receiver had been in need of the next of kin's care, and how many hours a week the next of kin gave care. Further questions were if the next of kin had their own illness, what kind of illness, if the next of kin had any support themselves, and what kind of support. The final questions concerned the care receiver's age, gender, illness and what kind of illness the person suffered from.

Data was also collected with the questionnaires Caregiver Burden Scale (CB Scale) [23], and the Subjective Estimation of Quality of Life (SQoL) [24] [25], presented below.

\subsubsection{Caregiver Burden Scale}

Elmståhl et al. [23] developed the CB Scale to assess the subjective burden in next of kin who care for another person, modified from a scale designed by Oremark [26]. The CB Scale is not disease specific, has been used in a different context, and is tested on families of patient groups [19] [23]. The CB Scale showed good construct validity and test-retest stability [23]. The questionnaire consists of five dimensions in which the items are summarized to get a total score for each dimension: General strain (8 items), Isolation (3 items), Disappointment (5 items), Emotional involvement (3 items), and Environment (3 items). The items have scores from 1 (Not At All) to 4 (Often). A higher score indicates a greater burden. The internal consistency in the present study was analysed with Cronbach's alpha and was acceptable for the dimensions General strain (0.85), Disappointment (0.74) and Emotional involvement (0.74). However, Cronbach's alpha was lower for the dimensions Environment (0.63) and Isolation (0.60). Coefficients in the vicinity of 0.70 may be adequate, especially for subscales, and coefficients of 0.80 or greater are highly desirable [27].

\subsubsection{Subjective Quality of Life}

Kajandi [24] developed the SQoL on the basis of Naess' [22] theoretical model. The questionnaire is intended both for healthy populations and for different diagnostic patient groups, adults and adolescents, making comparisons between different groups possible. The SQoL has been used in several previous studies concerning healthy groups: nursing students and people looking for work [24] [25]. The SQoL involves three dimensions with 18 items in total. The respondents evaluated the degree of satisfaction in his/her current life situation for each of these 18 items. The questionnaire has a scale with nine values $(1,1.5,2,2.5 \ldots)$, where five is the most positive rating. The dimension External life conditions consist of three items, concerning housing quality, work/ occupation quality, and personal economy, giving a total score from 3 to 15. The dimension Interpersonal relationships has five items concerning relationship to partner, relationship to friends, relationship to mother, relationship to father, and relationship to one's own children, giving a total score from 5 to 25. The third dimension, Internal psychological states, consists of nine items: engagement, energy, self-actualization, freedom, selfassuredness, self-acceptance, emotional experiences, security, and general mood, giving scores from 9 to 45 . In order to see how the different items relate to the assessment of the totality, the last item is a general estimation of Quality of Life as a whole, giving a total score from 1 to 5. Four of the items involve mutually exclusive alternative answers: Work/occupation quality (Have no work or meaningful occupation), Relationship to partner (Have no partner), Relationship to friends (Have no friends) and Relationship to one's own children (Have no children). Thus, a given score on one alternative excludes scoring on the other [25]. The instrument was chosen because of its acceptable stability and internal consistency, its theoretical perspective and its applicability to the next of kin. The internal consistency in the present study was analysed with Cronbach's alpha and had internal consistency for the eighteen items with a Cronbach's alpha of 0.88. Cronbach's alpha for the dimension Internal psychological states was (0.90): however, it was lower for the dimensions External life conditions (0.44) and Interpersonal relationships (0.56).

\subsection{Statistical Analysis}

Descriptive statistics were used to analyse the background data and also the SQoL and the CB Scale. Spear- 
man's Rho correlations were tested between the dimensions in the CB Scale and the different dimensions in the SQoL, QoL as a whole, and Quality of personal economy, gender, next of kin's own illness and civil status. As a question about "personal economy" was included in the SQoL, this question was analysed as part of the SQoL and also as an independent background variable. Mann-Whitney $U$ test was used to describe differences between male and female respondents regarding the CB Scale and the SQoL.

In all statistical analyses, probability values of $<0.05$ [26] were considered as statistically significant. To establish the internal reliability in the questionnaires and their dimensions, Cronbach's alpha coefficient was calculated [27].

\section{Results}

Twenty percent of the 84 respondents were male. The mean age for men was 59.2 years (Md $=66$, range 31 - 76 years) and for women 56.5 years $(\mathrm{Md}=56$, range 23 - 82 years). The women $(61 \%)$ were more often working outside the home than the men (35\%). In addition to being the next of kin to the care receiver, the men were more often retired (59\%) than the women (30\%). The male participants mostly cared for a spouse or an adult child, while the females cared for a spouse, an adult child or even parents to a greater extent than the males. Forty-seven percent of the males lived together with the care receiver, while sixty-one percent of the females did. Female participants reported having mental illnesses to a greater extent than the males. Few next of kin had their own support (Table 1). The next of kin had been caring for the care receiver from two months to 39 years, and from one to 168 hours week. However, most of the next of kin reported nonspecific intervals in terms of years or hours of giving care. Demographic data for care receiver are presented in Table 2.

\subsection{Results from the SQoL}

In general there were high estimations of the items in the SQoL. The highest overall ratings in the SQoL were for the items Housing quality and Relationship to one's own children (both median 5). The lowest ratings were found for the items Have no partner and Have no friends (median 2.0, respectively, 1.8). The results of the correlation analyses between the "QoL as a whole" and the 17 SQoL items showed that all items included in the di-

\section{Table 1. Demographic data for the next of kin.}

\begin{tabular}{|c|c|c|c|c|}
\hline Variable & Total $(n=84)$ & Male $(n=17)$ & Female $(n=67)$ & p-value \\
\hline $\begin{array}{l}\text { Age, mean (MD) } \\
\text { Range }\end{array}$ & $\begin{array}{c}57.1(57.0) \\
23-82\end{array}$ & $\begin{array}{c}59.2(66.0) \\
31-76\end{array}$ & $\begin{array}{c}56.5(55.5) \\
23-82\end{array}$ & 0.47 \\
\hline $\begin{array}{l}\text { Civil status, n (\%) } \\
\text { Cohabiting } \\
\text { Single } \\
\text { Living apart }\end{array}$ & $\begin{array}{c}69(82.1) \\
11(13.1) \\
4(4.8)\end{array}$ & $\begin{array}{c}16(94.1) \\
1(5.9) \\
0\end{array}$ & $\begin{array}{c}53(79.1) \\
10(14.9) \\
4(6.0)\end{array}$ & 0.33 \\
\hline $\begin{array}{l}\text { Relation to care receiver, } \mathbf{n} \text { (\%) } \\
\text { Spouse } \\
\text { Parent } \\
\text { Adult child } \\
\text { Sibling } \\
\text { Other }\end{array}$ & $\begin{array}{c}38(45.2) \\
23(27.4) \\
18(21.4) \\
1(1.2) \\
4(4.8)\end{array}$ & $\begin{array}{c}11(64.7) \\
1(5.9) \\
4(23.5) \\
0 \\
1(5.9)\end{array}$ & $\begin{array}{c}27(40.3) \\
22(32.8) \\
14(20.9) \\
1(1.5) \\
3(4.5)\end{array}$ & 0.00 \\
\hline Cohabiting with care receiver, n (\%) & $49(58.3)$ & $8(47.1)$ & $41(61.2)$ & 0.29 \\
\hline $\begin{array}{l}\text { Employment }^{*} \\
\text { Unemployd } \\
\text { Student } \\
\text { Work } \\
\text { Retired }\end{array}$ & $\begin{array}{c}4(4.8) \\
2(2.4) \\
47(56.6) \\
30(36.2)\end{array}$ & $\begin{array}{c}1(5.9) \\
0 \\
6(35.3) \\
10(58.8)\end{array}$ & $\begin{array}{c}3(4.6) \\
2(3.0) \\
41(62.1) \\
20(30.3)\end{array}$ & 0.15 \\
\hline $\begin{array}{l}\text { Have own illness } \\
\text { Somatic } \\
\text { Mental }\end{array}$ & $\begin{array}{c}33(39.8) \\
27(81.8) \\
6(18.2)\end{array}$ & $\begin{array}{c}6(35.3) \\
6(35.3) \\
0\end{array}$ & $\begin{array}{c}27(40.9) \\
21(31.8) \\
6(9.1)\end{array}$ & 0.54 \\
\hline $\begin{array}{l}\text { Support to the next of kin* } \\
\text { Call contacts } \\
\text { Respite care/assistant } \\
\text { Economic grant } \\
\text { Massage }\end{array}$ & $\begin{array}{c}19(22.9) \\
12(63.2) \\
5(26.2) \\
1(5.3) \\
1(5.3)\end{array}$ & $\begin{array}{c}2(11.8) \\
2(11.8) \\
0 \\
0 \\
0\end{array}$ & $\begin{array}{c}17(25.8) \\
10(15.2) \\
5(7.6) \\
1(1.5) \\
1(1.5)\end{array}$ & 0.84 \\
\hline
\end{tabular}

${ }^{*} \mathrm{n}=83$. 
Table 2. Demographic data for the care receiver.

\begin{tabular}{lccc}
\hline Variable & Total $\mathbf{n}=\mathbf{9 2}$ & $\begin{array}{c}\text { Male } \mathbf{n}=\mathbf{5 4} \\
\mathbf{( 5 8 . 7 \% )}\end{array}$ & $\begin{array}{c}\text { Female } \mathbf{n}=\mathbf{3 8} \\
\mathbf{( 4 1 . 3 \% )}\end{array}$ \\
\hline Age, mean (MD) & $56.7(68.0)$ & $66.0(65.0)$ & $54.6(69.5)$ \\
Range & $5-93$ & $5-90$ & $9-93$ \\
Illness indicated by next of kin* & $88(100.0)$ & $52(59.0)$ & $36(41.0)$ \\
Somatic & $62(70.5)$ & $34(65.0)$ & $28(78.0)$ \\
Mental & $26(29.5)$ & $18(35.0)$ & $8(22.0)$ \\
\hline
\end{tabular}

${ }^{*} \mathrm{n}=88$, next of kin did not report specificillness.

mension External life conditions and the dimension Internal psychological states were significantly correlated with the "QoL as a whole”, with the highest significance for security and general mood. From the dimension Interpersonal relationships correlations, Have no partner, Have no friends, Relationships to mother and Have no children were non-significant. Ratings for all items in the questionnaire are shown in Table 3.

\subsection{Correlations between the CB Scale, SQoL and Socio-Economic Factors}

Correlations between the CB Scale (all five dimensions), the SQoL (all three dimensions), “QoL as a whole”, and the item Quality of personal economy, gender, next of kin's own illness and civil status, are shown in Table 4. In general, high estimations were found in the dimensions in the CB Scale and high correlations were found between the dimensions. Worth mentioning, however, is that civil status had no correlation with any of the included variables, and gender had only significant correlations with Disappointment ( $<<0.05)$, Emotional involvement ( $p<0.01)$, and Quality of personal economy ( $<<0.01)$ (Table 4).

These findings were also confirmed in the further analyses with the Mann-Whitney $U$ test of all included variables, comparing male and female next of kin, where only the dimensions Disappointment and Emotional involvement from the CB Scale and Quality of personal economy from the SQoL showed significant differences between genders. Male next of kin scored significantly lower in both Disappointment $(\mathrm{p}=0.02)$ and Emotional involvement $(\mathrm{p}<0.01)$ than the female, who, on the other hand, rated their Quality of personal economy significantly lower $(\mathrm{p}<0.01)$ than the male. Mean values for the different dimensions from the SQL and CB Scale are shown in Table 5. Worth noticing is that the mean values are rather high for all dimensions as well as for Quality of Life as a whole.

\section{Discussion}

In the present study, high estimations and correlations were found in Subjective Quality of Life for all dimensions as well as for Quality of Life as a whole, and in the CB Scale dimensions. The results show that the next of kin experienced a high burden, although they at the same time experienced a good quality of life. A phenomenon for all subjective quality of life scales is that the respondent relatively quickly adapts to a new situation and then estimates slightly above average on the scale, although the subjective instruments will capture changes that happened recently (Personal communication, Kajandi 2013). However, findings in next of kin of persons with heart failure regarding experienced QoL, burden, and life situation in general among next of kin showed caregiver burden and depression correlated with lower QoL [28], socio-economic status, and to be a female correlated with lower QoL [29].

The results in the present study also showed that gender had significant correlations with Disappointment and Emotional involvement. Further analyses showed that female next of kin to a higher extent were disappointed and more emotionally involved in the care receiver than the male next of kin. In line with these findings are the results by Larson et al. [30], who among next of kin of persons with stroke found that male spouses had a lower occurrence of emotional involvements in their social network, and that female spouses had a negative impact on psychological well-being. Twigg and Atkin [31] stated that male next of kin appear to find it easier to separate themselves from the caring situation; they set limits on their involvement, while females are more likely to subordinate their interest to those of the person they care for. Dykstra and De Jong Gierveld [32] mean that women are traditionally socialized to be nurturing and family oriented. Women do more family work and more often fulfil the role of guardian.

Female next of kin in the present study also estimated their economic situation as more unsatisfactory than the 
Table 3. Estimation of SQoL in next of Kin $(n=84)$. Correlations between separate items and the rating of QoL as a whole in the SQoL.

\begin{tabular}{|c|c|c|c|c|c|c|}
\hline Dimension item & $\mathrm{n}$ & Md & IQR & M & $\mathrm{SD}$ & $\begin{array}{l}\text { Item's correlation with } \\
\text { QoL as a whole }\end{array}$ \\
\hline \multicolumn{7}{|l|}{ External life conditions (total score) } \\
\hline 1. Housing quality & 83 & 5 & $4.0-5.0$ & 4.4 & 0.9 & $0.30^{* *}$ \\
\hline \multicolumn{7}{|l|}{ 2. Work/occupation quality } \\
\hline a. Have work/meaningful occupation & 65 & 3.5 & $3.0-4.0$ & 3.5 & 0.9 & $0.50^{* *}$ \\
\hline b. Have no work/meaningful occupation & 19 & 3.0 & $2.0-4.0$ & 2.9 & 1.1 & $0.63^{* *}$ \\
\hline 3. Quality of personal economy & 83 & 4.0 & $3.0-4.5$ & 3.5 & 1.1 & $0.23^{* *}$ \\
\hline \multicolumn{7}{|l|}{ Interpersonal relationships (total score) } \\
\hline \multicolumn{7}{|l|}{ 4. Relationship to partner } \\
\hline a. Have a partner & 75 & 3.5 & $2.5-4.5$ & 3.2 & 1.5 & $0.45^{* *}$ \\
\hline b. Have no partner & 9 & 2.0 & $1.0-3.0$ & 2.2 & 1.1 & ns \\
\hline \multicolumn{7}{|l|}{ 5. Relationship to friends } \\
\hline a. Have friends & 76 & 4.0 & $3.0-4.5$ & 3.7 & 1.0 & $0.42^{* *}$ \\
\hline b. Have no friends & 6 & 1.8 & $1.0-2.3$ & 1.8 & 0.8 & ns \\
\hline 6. Relationship to mother & 81 & 4.0 & $3.0-5.0$ & 3.6 & 1.3 & ns \\
\hline 7. Relationship to father & 80 & 4.0 & $3.0-4.9$ & 3.6 & 1.3 & $0.31^{* *}$ \\
\hline \multicolumn{7}{|l|}{ 8. Relationship to own children } \\
\hline a. Have own children & 76 & 5.0 & $4.1-5.0$ & 4.5 & 0.8 & $0.23^{*}$ \\
\hline b. Have no own children & 8 & 3.0 & $1.3-3.0$ & 2.6 & 1.2 & ns \\
\hline \multicolumn{7}{|l|}{ Internal psychological states (total score) } \\
\hline 9. Engagement & 82 & 4.0 & $3.0-4.5$ & 3.7 & 1.1 & $0.50^{* *}$ \\
\hline 10. Energy & 82 & 3.0 & $2.0-4.0$ & 3.1 & 1.1 & $0.59^{* *}$ \\
\hline 11. Self-actualization & 81 & 3.5 & $3.0-4.0$ & 3.3 & 0.9 & $0.66^{* *}$ \\
\hline 12. Freedom & 82 & 3.0 & $2.0-4.0$ & 3.0 & 1.2 & $0.53^{* *}$ \\
\hline 13. Self-assuredness & 82 & 4.0 & $3.4-4.5$ & 3.8 & 0.8 & $0.64^{* *}$ \\
\hline 14. Self-acceptance & 81 & 4.0 & $3.3-4.5$ & 3.9 & 0.9 & $0.58^{* *}$ \\
\hline 15. Emotional experiences & 83 & 4.0 & $3.5-5.0$ & 4.2 & 0.9 & $0.52^{* *}$ \\
\hline 16. Security & 83 & 3.0 & $2.0-4.0$ & 3.2 & 1.1 & $0.70^{* *}$ \\
\hline 17. General mood & 83 & 3.0 & $3.3-4.0$ & 3.2 & 1.0 & $0.72^{* *}$ \\
\hline 18. QOL as a whole & 83 & 3.5 & $3.0-4.0$ & 3.5 & 0.9 & - \\
\hline
\end{tabular}

Note. A higher value indicates a more positive estimated quality of life. SQoL $=$ subjective quality of life; IQR $=$ Interquartile range $\left(25^{\text {th }}-75^{\text {th }}\right.$ percentile). ${ }^{*} \mathrm{p}>0.05$. $^{* *} \mathrm{p}>0.01$. $^{* * *}$ Spearman rank correlation (Rho). ns = Non-significant.

male next of kin. Van Houtven [33] showed that female next of kin, who remain working, decreased their work with 3 - 10 hours per week which gave a three percent lower wage. There was not the corresponding impact in caregiving hours and lower wages among male informal caregivers. Schneider et al. [34] found time-based conflicts between informal eldercare and paid work. It was positively related to job changes of female workers but not of their male counterparts. Quality of personal economy also correlated with a lower QoL. Other studies have also determined that next of kin with poor economic status had a lower QoL, as next of kin of stroke patients [35], multiple sclerosis patients [14], heart failure patients [36], and older next of kin of persons with impaired health [37]. 
Table 4. Correlations of CB Scale, SQoL, “Quality of life as a whole”, Quality of personal economy and demographic data for next of kin.
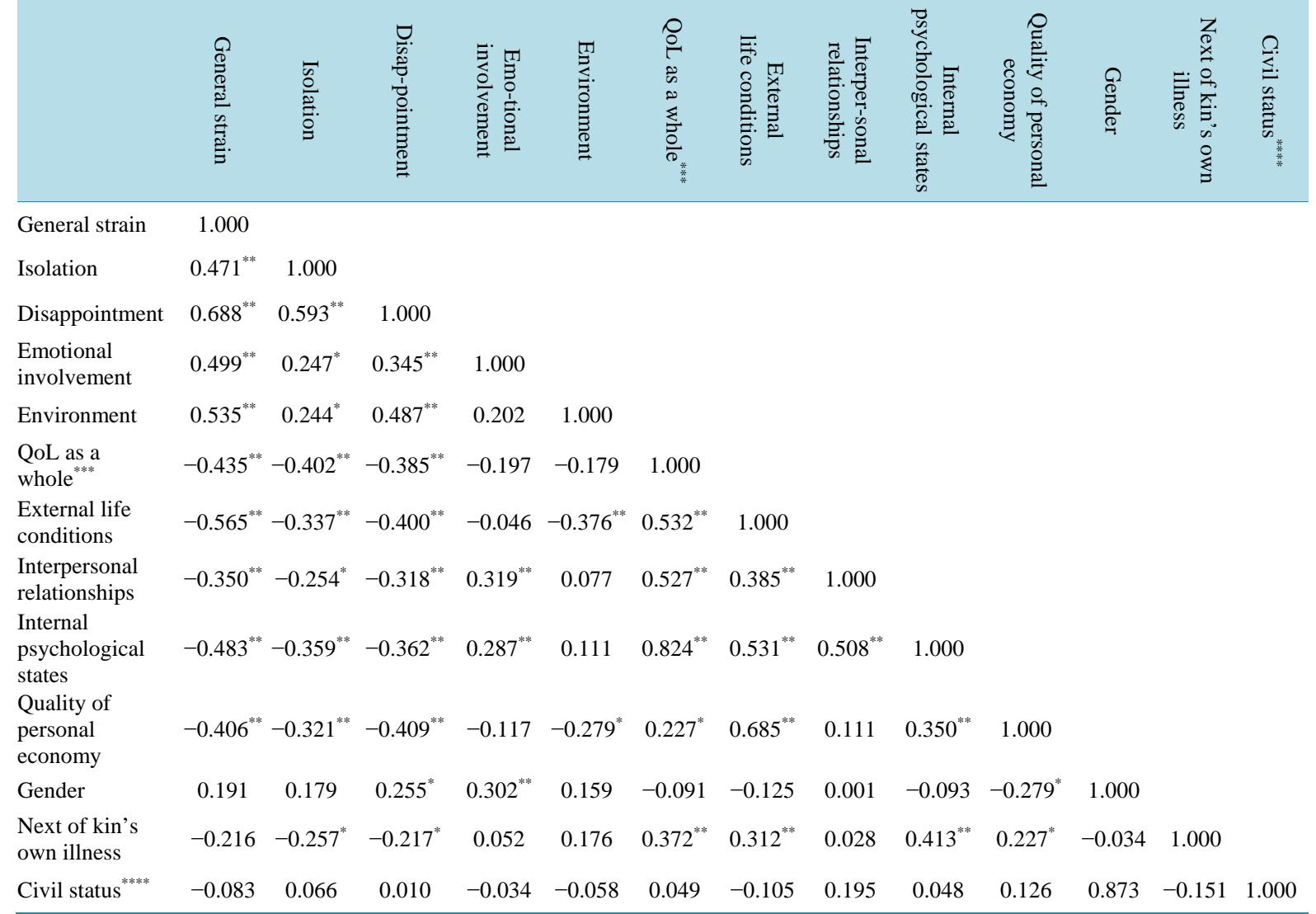

${ }^{*}$ Correlation is significant at the 0.05 level (2-tailed). ${ }^{* *}$ Correlation is significant at the 0.01 level (2-tailed). ${ }^{* * *}$ Quality of life as a whole (Kajandi).

Table 5. Descriptive statistics for the five dimensions in Elmståhl's CB Scale, the dimensions in Kajandi’s SQoL, “Quality as a whole”, Quality of personal economy from the SQoL in terms of male/female participants.

\begin{tabular}{|c|c|c|c|c|c|c|c|c|c|c|c|c|c|}
\hline \multirow[b]{2}{*}{ Instrument } & \multicolumn{4}{|c|}{ All participants $(n=84)$} & \multicolumn{4}{|c|}{ Male participants $(\mathrm{n}=17)$} & \multicolumn{5}{|c|}{ Female participants $(n=67)$} \\
\hline & M & $\mathrm{SD}$ & Md & IQR & M & SD & Md & IQR & M & SD & Md & IQR & $\begin{array}{c}\mathrm{p}- \\
\text { value }\end{array}$ \\
\hline \multicolumn{14}{|l|}{ (Elmståhl) dimensions: } \\
\hline General strain & 3.08 & 0.61 & 3.25 & $2.75-3.50$ & 2.77 & 0.79 & 3.00 & $2.19-3.44$ & 3.16 & 0.54 & 3.25 & $2.75-3.50$ & 0.08 \\
\hline Isolation & 2.81 & 0.68 & 3.00 & $2.33-3.33$ & 2.53 & 0.81 & 2.67 & $2.00-3.16$ & 2.89 & 0.64 & 3.00 & $2.33-3.33$ & 0.10 \\
\hline Disappointment & 2.82 & 0.69 & 3.00 & $2.45-3.40$ & 2.44 & 0.80 & 2.60 & $1.80-3.10$ & 2.91 & 0.63 & 3.00 & $2.60-3.40$ & $<0.02$ \\
\hline Emotional involvement & 2.36 & 0.77 & 2.33 & $1.67-3.00$ & 1.88 & 0.74 & 2.00 & $1.00-2.50$ & 2.48 & 0.73 & 2.67 & $1.67-3.00$ & $<0.01$ \\
\hline Environment & 2.34 & 0.79 & 2.33 & $1.67-2.91$ & 2.06 & 0.75 & 2.00 & $1.50-2.67$ & 2.41 & 0.79 & 2.33 & $2.00-3.00$ & 0.15 \\
\hline \multicolumn{14}{|l|}{ (Kajandi) dimensions: } \\
\hline External life conditions ${ }^{* *}$ & 11.35 & 2.08 & 11.50 & $10.38-13.00$ & 11.74 & 1.64 & 11.50 & $11.50-12.50$ & 11.25 & 2.18 & 11.50 & $10.00-13.00$ & 0.40 \\
\hline $\begin{array}{l}\text { Interpersonal } \\
\text { relationships }\end{array}$ & 18.45 & 3.56 & 19.00 & $16.00-21.00$ & 18.53 & 4.06 & 19.00 & $15.00-22.50$ & 18.43 & 3.44 & 18.75 & $16.00-21.00$ & 0.99 \\
\hline $\begin{array}{l}\text { Internal psychological } \\
\text { states }^{* * * *}\end{array}$ & 31.23 & 6.59 & 32.50 & $27.00-35.38$ & 32.79 & 7.30 & 34.50 & $27.00-36.50$ & 30.81 & 6.39 & 31.50 & $27.00-35.00$ & 0.27 \\
\hline QoL as a whole & 3.45 & 0.91 & 3.50 & $3.00-4.00$ & 3.65 & 0.92 & 4.00 & $3.00-4.00$ & $3.40^{*}$ & $0.91^{*}$ & $3.50^{*}$ & $2.50-4.00^{*}$ & 0.41 \\
\hline $\begin{array}{l}\text { Quality of personal } \\
\text { economy }^{* * * * *}\end{array}$ & 3.54 & 1.14 & 4.00 & $3.00-4.50$ & 4.15 & 0.79 & 4.00 & $4.00-4.75$ & $3.39^{*}$ & $1.17^{*}$ & 3.50 & $3.00-4.13$ & $<0.01$ \\
\hline
\end{tabular}


The female next of kin in the present study reported to a greater extent her own mental illness. This finding is also in agreement with findings, for example, among next of kin of persons with heart failure [36]. Gallicchio et $a l$. [38] found that female caregivers of demented persons had a higher burden and depression than male caregivers. Brazil et al. [39] found a significant greater level of caregiving strain among female than male caregivers, when caring for a person at the end of life. Li et al. [40] found that female spousal caregivers had a lower mental and physical health, lower life satisfaction, decreased marital satisfaction and a poorer health related QoL than the male.

Worth mentioning, however, is that civil status had no correlation with any of the included variables. In a study with the aim to explore what kind of support next of kin of older persons receive from respite care, they found that next of kin who lived alone were more satisfied with their quality of life than those who lived together with the care receiver [41]. On the other hand, in the present study, it seems important with Interpersonal relations, which correlates with the CB Scale except for Environment. In the present study the next of kin have rated their relationship to others as good. Also in an earlier study of next of kin of persons with multiple sclerosis, the results showed significant correlations between QoL as a whole and relationship with friends [42].

Next of kin may experience caregiving to another person as a voluntary act of compassion, satisfying and enriching, and the next of kin does not experience any feeling of burden. Informal caregiving can, on the other hand, be experienced as an unavoidable obligation; it may be experienced as a process of loss, grief or impoverishment. It can be difficult to stop caregiving because it is tantamount to abandoning the care receiver. The impact of freedom of choice is visible in the quality of the relationship and the next of kin's psychosocial wellbeing [10].

The strength of structured questionnaires is the ability to collect unambiguous answers and cover a large, geographically spread population relatively quickly and economically [43]. One disadvantage of using the different association's websites to reach potential participants may be that only those who had computer skills and access to a computer could read the information regarding recruitment to the present study. It may have been difficult to reach the very oldest next of kin because they are not users of computers to the same extent as younger persons. However, the recruitment was also made through monthly journals and personal meetings with personnel at the associations. The age of the participants ranged up to 82 years of age, indicating that it was still possible to recruit older participants in this way. A disadvantage was that there were no statistical analyses made of the next of kin's caring in terms of years or hours a week, since this was due to the highly varying and unspecific reported data. Worth mentioning is also that no medical diagnosis was confirmed, as the illness of the care receiver and the next of kin's own illness were reported only by the next of kin.

In the present study, $20 \%$ of the participants were male next of kin. The ideal would have been to have an equal number of male and female participating in the study. However, this was not possible to control due to the used recruitment process. The strength of the recruitment process, however, was that the study did not limit participation to next of kin to persons with a specific illness or disability.

\section{Conclusions}

The experience of being a next of kin in the role as informal caregiver is complex, as it has an impact on all aspects of the next of kin's life situation. It is important to take the individual differences under consideration when designing a nursing intervention, to meet the different needs and demands of the male and female next of kin. These interventions should focus on individual support, so that the caregivers can adapt to their new role and be comfortable and effective as informal caregivers.

It is of importance for healthcare personnel to have a general knowledge and ability to understand the next of kin's life situation, regardless of the care receiver's diagnosis, as they meet next of kin to persons in need of care within all healthcare and social care in society.

\section{Relevance for Clinical Practice}

From the results in the present study, a need for concrete, general and simple tools for the healthcare personnel are necessary to be able to meet the next of kin's needs in different situations.

Good care can only be delivered where there is a triadic relationship. All persons have a key role to play and have unique knowledge to contribute. Further, all persons should experience a sense of security (feeling safe), a sense of continuity (perceiving links and connections), a sense of belonging (feeling a part of things), a sense of 
purpose (having one or more goals to aspire to), a sense of achievement (making progress towards these goals), and a sense of significance (feeling that they matter as a person). These are adapted from Nolan's et al. [44] Partnership Model.

The model is a way of closer co-operation between on the one hand the care receiver and his/her next of kin, and on the other hand the care personnel. The "six senses" in this framework/model are all seen as prerequisites for good communication and good relationships. When the Partnership Model is to be applied, the "Carers Outcome Agreement Tool" (COAT) can be used, which is a scientifically designed instrument for planning, monitoring and evaluation of support for the next of kin. The instrument is designed to increase the collaboration between the healthcare personnel, and the purpose of the COAT is to develop a working model that works well for next of kin, the care receiver, and the personnel [45].

\section{Acknowledgements}

The study was supported by the Örebro Nutrition and Physical Activity Research Centre for Optimal Health and Functionality through Life (NUPARC) and Maja Johansson's and Maria Brantefor's Scholarship Fund for development for work in health care.

\section{References}

[1] World Health Organisation (WHO) (2002) Current and Future Long-Term-Care Needs. World Health Organization, Geneva, WHO/NMH/CCL/02.2. http://whqlibdoc.who.int/hq/2002/WHO_NMH_CCL_02.2.pdf

[2] The National Alliance for Caregiving (NAC) (2013) Advanced Family Caregiving. Through Research, Innovation and Advocacy. http://www.caregiving.org/research

[3] Health and Social Care Information Centre (2010) https://catalogue.ic.nhs.uk/publications/social-care/surveys/surv-care-hous-eng-2009-2010/comp-res-surv-care-eng-20 09-2010-rep2.pdf

[4] The National Board of Health and Welfare (2009) Support for Families Requires Strategy. Announcement Sheet. http://socialstyrelsen.se/publikationer2009

[5] Boström, K., Ahlström, G. and Sunvisson, H. (2006) Being the Next of Kin of an Adult Person with Muscular Dystrophy. Clinical Nursing Research, 15, 86-106. http://dx.doi.org/10.1177/1054773805285706

[6] Philips, L. and Reed, P. (2009) Into the Abyss of Someone Else's Dying: The Voice of the End-of-Life Caregiver. Clinical Nursing Research, 18, 80-97. http://cnr.sagepub.com/content/18/1/80 http://dx.doi.org/10.1177/1054773808330538

[7] Department of Public Health (2010) Informal Caregiving: Implications for Public Health. County of Los Angeles. http://publichealth.lacounty.gov/ha/reports/habriefs/2007/Caregiving_Final.pdf

[8] Carretero, S., Garcés, J., Ródenas, F. and Sanjosé, V. (2009) The Informal Caregiver’s Burden of Dependent People: Theory and Empirical Review. Archives of Gerontology and Geriatrics, 49, 74-79. http://dx.doi.org/10.1016/j.archger.2008.05.004

[9] Stoltz, P. (2006) Searching for the Meaning of Support in Nursing: A Study on Support in Family Care of Frail Aged Persons with Examples from Palliative Care at Home. Dissertation, Malmö University, Malmö.

[10] Zegwaard, M.I., Aartsen, M.J., Grypdonck, M.H.F. and Cuijpers, P. (2013) Differences in Impact of Long Term Caregiving for Mentally Ill Older Adults on the Daily Life of Informal Caregivers: A Qualitative Study. BMC Psychiatry, 13, 103. http://www.biomedcentral.com/1471-244X/13/103 http://dx.doi.org/10.1186/1471-244X-13-103

[11] Minnes, P., Woodford, L., Carlson, P., Johnston, J. and McColl, M.A. (2010) The Needs of Aging Parents Caring for an Adult with Acquired Brain Injury. Canadian Journal on Aging, 29, 185-192. http://dx.doi.org/10.1017/S0714980810000103

[12] Coy, A.E., Perrin, P.B., Stevens, L.F., Hubbard, R., Díaz Sosa, D.M., Espinosa Jove, I.G. and Arango-Lasprilla, J.C. (2013) Moderated Mediation Path Analysis of Mexican Traumatic Brain Injury Patient Social Functioning, Family Functioning, and Caregiver Mental Health. Archives of Physical Medicine and Rehabilitation, 94, 362-368. http://dx.doi.org/10.1016/j.apmr.2012.08.210

[13] Williams, J.K., Skriton, H., Paulsen, J.S., Tripp-Reimer, T., Jarmon, L., McGonigal Kenney, M., Birrer, E., Hennig, B.L. and Honeyford, J. (2008) The Emotional Experiences of Family Carers in Huntington Disease. Journal of Advanced Nursing, 65, 789-798. http://dx.doi.org/10.1111/j.1365-2648.2008.04946.x

[14] Buhse, M. (2008) Assessment of Caregiver Burden in Families of Persons with Multiple Sclerosis. Journal of Neuro- 
science Nursing, 40, 25-31. http://dx.doi.org/10.1097/01376517-200802000-00005

[15] Larson, J. (2005) Life Situation after Stroke-The Spouses’ Perspective. Dissertation, Karolinska Institutet, Stockholm.

[16] Samuelsson, A.M., Annerstedt, L., Elmståhl, S., Samuelsson, S.M. and Grafström, M. (2001) Burden of Responsibility Experienced by Family Caregivers of Elderly Dementia Suffers, Analysis of Strain, Feelings and Coping Strategies. Scandinavian Journal of Caring Sciences, 15, 25-33. http://dx.doi.org/10.1046/j.1471-6712.2001.1510025.x

[17] Zarit, S.H., Reever, K.E. and Bach-Peterson, J. (1980) Relatives of the Impaired Elderly: Correlates of Feelings of Burden. The Gerontologist, 20, 649-655. http://dx.doi.org/10.1093/geront/20.6.649

[18] Montgomery, R.J.V., Gonyea, J.G. and Hooyman, N.R. (1985) Caregiving and the Experience of Subjective and Objective Burden. Family Relations, 34, 19-26. http://dx.doi.org/10.2307/583753

[19] Andrén, S. (2006) Family Caregivers of Persons with Dementia. Experiences of Burden, Satisfaction and Psychosocial Intervention. Dissertation, Lund University, Lund.

[20] Sandau, K.E., Bredow, T.S. and Peterson, S.J. (2009) Health-Related Quality of Life. In: Peterson, S.J. and Bredow, T.S., Eds., Middle Range Theories: Application to Nursing Research, 2nd Edition, Wolters Kluwer/Lippincott Williams \& Wilkins, Philadelphia.

[21] Fayers, P.M. and Machin, D. (2007) Quality of Life, the Assessment, Analysis and Interpretation of Patient-Reported Outcomes. 2nd Edition, Wiley, Chichester.

[22] Naess, S. (1987) Quality of Life Research: Concepts, Methods and Applications. Institute of Applied Social Science, Oslo.

[23] Elmeståhl, S., Malmberg, B. and Annerstedt, L. (1996) Caregiver’s Burden of Patients 3 Years after Stroke Assessed by a Novel Caregiver Burden Scale. Archives of Physical Medicine and Rehabilitation, 77, 177-182. http://dx.doi.org/10.1016/S0003-9993(96)90164-1

[24] Kajandi, M. (1994) A Psychiatric and Interactional Perspective on Quality of Life in Concerts and Measurement of Quality of Life. In: Nordenfelt, L., Ed., Health Care, Kluwer Academic Publishers, Dordrecht, 257-277.

[25] Kajandi, M. (2006) Studies on Quality of Life. A Methodological Perspective on the Definition and Measurement of the Good Life in Patients with Psychiatric Illness. Dissertation, Uppsala Dissertation from the Faculty of Medicine 9, Acta Universitatis Upsaliensis, Uppsala.

[26] Oremark, I. (1988) ABS-A Next of Kin Load Scale. Proceedings from the IXth Nordic Congress of Gerontology, Bergen, 5 June 1988.

[27] Polit, D.F. and Beck, C.T. (2012) Nursing Research, Generating and Assessing Evidence for Nursing Practice. 9th Edition, Wolters Kluwer Health/Lippincott Williams \& Wilkins, Philadelphia.

[28] Hooley, P.J.D., Butler, G. and Howlett, J.G. (2005) The Relationship of Quality of Life, Depression and Caregiver Burden in Outpatients with Congestive Heart Failure. Congestive Heart Failure, 11, 303-310. http://dx.doi.org/10.1111/j.1527-5299.2005.03620.x

[29] Javaid, I., Loraine, F., Janet, R., Scott, M. and Martin, D. (2010) Quality of Life in Patients with Chronic Heart Failure and Their Carers: A 3-Year Follow-Up Study Assessing Hospitalization and Mortality. European Journal of Heart Failure, 12, 1002-1008. http://dx.doi.org/10.1093/eurjhf/hfq114

[30] Larson, J., Franzén-Dahlin, A., Billing, E., Von Arbin, M., Murray, V. and Wredling, R. (2008) The Impact of Gender Regarding Psychological Well-Being and General Life Situation among Spouses of Stroke Patients during the First Year after the Patients' Stroke Event: A Longitudinal Study. International Journal of Nursing Studies, 45, 257-265. http://dx.doi.org/10.1016/j.ijnurstu.2006.08.021

[31] Twigg, J. and Atkin, K. (2002) Carers Perceived: Policy and Practice in Informal Care. Open University Press, Philadelphia.

[32] Dykstra, P.A. and De Jong Gierveld, J. (2004) Gender and Marital-History Differences in Emotional and Social Loneliness among Dutch Older Adults. Canadian Journal on Aging, 23, 141-155. http://dx.doi.org/10.1353/cja.2004.0018

[33] Van Houtven, C.H., Coe, N.B. and Skira, M.M. (2013) The Effect of Informal Care on Work and Wages. Journal of Health Economics, 32, 240-252. http://dx.doi.org/10.1016/j.jhealeco.2012.10.006

[34] Schneider, U., Trukeschitz, B., Mühlmann, R. and Ponocny, I. (2013) “Do I Stay or Do I Go”-Job Change and Labor Market Exit Intentions of Employees Providing Informal Care to Older Adults. Health Economics, 22, 1230-1249.

[35] Larson, J., Franzén-Dahlin, A., Billing, E., Von Arbin, M., Murray, V. and Wredling, R. (2005) Predictors of Quality of Life among Spouses of Stroke Patients during the First Year after the Stroke Event. Scandinavian Journal of Caring Sciences, 19, 439-445. http://dx.doi.org/10.1111/j.1471-6712.2005.00369.x

[36] Whittingham, K., Barnes, S. and Gardiner, C. (2013) Tools to Measure Quality of Life and Carer Burden in Informal 
Carers of Heart Failure Patients: A Narrative Review. Palliative Medicine, 27, 596-607. http://dx.doi.org/10.1177/0269216313477179

[37] Ekwall, A., Sivberg, B. and Hallberg, I.R. (2004) Dimensions of Informal Care and Quality of Life among Elderly Family Caregivers. Scandinavian Journal of Caring Sciences, 18, 239-248. http://dx.doi.org/10.1111/j.1471-6712.2004.00283.x

[38] Gallicchio, L., Nauman, S., Langenberg, P. and Baumgarten, M. (2002) Gender Differences in Burden and Depression among Informal Caregivers of Demented Elders in the Community. International Journal of Geriatric Psychiatry, 17, 154-163.

[39] Brazil, K., Thabane, L., Foster, G. and Bédard, M. (2009) Gender Differences among Canadian Spousal Caregivers at the End of Life. Health \& Social Care in the Community, 17, 159-166.

[40] Li, Q.P., Mak, Y.W. and Loke, A.Y. (2013) Spouses’ Experience of Caregiving for Cancer Patients: A Literature Review. International Nursing Review, 60, 178-187.

[41] Salin, S., Kaunonen, M. and Åstedt-Kurki, P. (2009) Informal Carers of Older Family Members: How They Manage and What Support They Receive from Respite Care. Journal of Clinical Nursing, 18, 492-501. http://dx.doi.org/10.1111/j.1365-2702.2008.02550.x

[42] Liedström, E., Isaksson, A.K. and Ahlström, G. (2010) Quality of Life in Spite of an Unpredictable Future: The Next of Kin of Patients with Multiple Sclerosis. Journal of Neuroscience Nursing, 42, 331-341.

[43] Bowling, A. (2009) Research Methods in Health: Investigating Health and Health Services. 3rd Edition, Open University Press, Buckingham.

[44] Nolan, M., Grant, G., Keady, J. and Lundh, U. (2003) New Directions for Partnership: Relationship-Centered Care. In: Nolan, M., Lundh, U., Grant, G. and Keady, J., Eds., Partnership in Family Care: Understanding the Caregiving Career, Open University Press, Philadelphia.

[45] Hanson, E., Magnusson, L. and Nolan, J. (2008) Swedish Experiences of Negotiated Approach to Carer Assessment: The Carers Outcome Agreement Tool. Journal of Research in Nursing, 13, 391-407. http://dx.doi.org/10.1177/1744987108095161 